\title{
Phase planning today
}

\section{Planificación por fases ahora}

\author{
Steve Knapp*1, Roberto Charron*, Gregory How ell* \\ * Lean Project Consulting, Louisville, USA \\ Best paper award \\ 14th Annual Conference of the \\ International Group for Lean Construction \\ July 25-27 2006 - Santiago Chile \\ PAG. 157 - 162
}

\begin{abstract}
Since the publication of W hite Paper \#7 "Phase Scheduling" (Ballard, 2000), work on many projects has been planned with this technique by teams of varying configuration. Many teams have adapted their own approach to developing a "phase schedule", in some cases called a "reverse phase schedule" or a "pull phase schedule". During these planning sessions, ideas have been put in practice that improve on the original scheme and increase the benefits of producing a phase schedule. Perhaps the most significant being the conversations that the teams pursue during the exercise. This paper will briefly describe the authors' current approach to and practices for preparing phase schedules and how this has become, in actuality, phase planning. It will then describe how phase planning produces the project schedule as traditionally understood, and more importantly designs the network of commitments necessary to deliver each project milestone, and how understanding and using the network of commitments improves project performance.
\end{abstract}

Keywords: Phase planning, scheduling

Resumen

Desde la publicación del artículo "Programación por Fases" (Ballard, 2000), el trabajo en muchos proyectos han sido planeado utilizando esta técnica con equipos de configuración variable. Muchos equipos han adaptado su propio enfoque para desarrollar "programación por fases", en algunos casos incluso llamada "programación por fases inversa" o "programación por fases por arrastre". Durante las sesiones de planificación, algunas ideas han sido puestas en práctica que mejoran el esquema original e incrementan los beneficios programas por fases. Tal ves uno de los mayores beneficios son las conversaciones que los equipos mantienen durante el ejercicio de programación. Este artículo describe brevemente el enfoque y prácticas de los autores para preparar programación por fases y como esto ha llegado a ser, en realidad, planificación por fases. El artículo describe como la planificación por fases no solo produce un programa de proyecto como se entiende tradicionalmente, sino además diseña una red de compromisos. Se explica como dicha red es necesaria para obtener cada hito del proyecto y de cómo el entender y utilizarla mejora el desempeño del proyecto.

Palabras Clave: Planificación por fases, programación

\section{Introducción}

White Paper \#7 "Phase Scheduling" was issued in April 2000 by the Lean Construction Institute (Ballard, 2000). It recommends the use of pull techniques and team planning to develop a schedule for each project phase. A phase is identified, usually with a start date, finish date and very brief description (building skin, excavation and slab on grade, preparation of construction drawings, etc.) from the project master or milestone schedule. The team, including representatives of each organization working on the phase, gathers together in a room. Each person then writes on a small piece of paper

\footnotetext{
1 Autor de correspondencia / Corresponding autor: Lean Project Consulting, 625 Main St 1B, Louisville, CO 80027. Phone 303-717-0952, E-mail address: sknapp@leanproject.com
}

(later to be stuck on the wall - thus "stickies") their task or the work that they will perform to release work to another team member. These "stickies" are placed, on the wall or a long piece of paper, moved around to reflect the way the work will actually be performed, discussed, adjusted, until finally a logic network is available. Typically the team starts from the end of the phase and works toward the beginning of the phase as they describe and place their tasks on the wall thus adding only the work that has to be done.

The team then adds durations to the tasks, again discusses, moves the "stickies", applies more or less resources and determines the duration for the entire phase. The White Paper stresses that these durations 
should be the team members' "best" estimate of the actual time that will be spent, in other words without any contingency time included. This duration will either meet the requirements from the master schedule or not, the team will make the necessary adjustments to arrive at a practical end date and most importantly "publicly generate, quantify and allocate schedule contingency (float)". According to the White Paper, this schedule, with its publicly allocated float, has the "force of contract" and can only be changed when the prime contract is changed, the team agrees that they cannot meet the schedule or finds a better, faster way to do the job. Development of a phase schedule is an integral part of the application of the Last Planner System to a project. In fact, the phase schedule is the basis for a 6 W eek Lookahead Plan and ultimately the Weekly Work Plan, all essential components of the Last Planner System ${ }^{\circledR}$ (LPS). In this paper the authors will describe their experience with Phase Scheduling, in particular how they see it as being more than just a means of preparing a better and more effective $G$ antt chart type schedule for a project.

\section{Experience and development}

The authors have participated in dozens of phase scheduling sessions. Contrary to the W hite Paper, none of these have ended with a contractually binding schedule; instead, virtually all of them have provided something more valuable - a team that understands their project, their individual roles and what is required for success on the project. Here are a number of actual but disguised examples of how phase scheduling sessions have worked.

\section{Case 1}

Project: Cancer Center

Phase: From opening ground to steel erection Participants: General Contractor (GC), relevant subs, chief nurse, architect, engineer, owner project manager (PM), facilitator

Eureka moment: Erect steel prior to placing and curing slab on grade (SO G) - saved 6 weeks of construction time

Discussion: The subs had not worked together before but the $G C$ and $O$ wner had. A senior nurse and architect began the meeting with a much-appreciated explanation of the value to be delivered by the project. This was followed by a simple demonstration of phase planning on a very small piece of the project. The session was facilitated by the GC PM. As the phase plan developed, it became obvious that the steel could be erected without the SO G however the phase chosen was too large and complex for an initial session. The phase plan, "the stickies" were converted to Microsoft Project and used to manage the phase.

\section{Case 2}

Project: New wing on existing children's hospital Phase: Completion of excavation to basement SO G poured

Participants: Architect, engineer, GC, relevant subs, facilitator

Eureka moment: M any smaller moments. First planned pour was completed nearly 4 weeks earlier than originally scheduled before the meeting. Discussion: The subs were already working together on site. The session was led by the project superintendent who allowed and encouraged deep discussion of the issues. The resulting interaction between subs developed a strategy for the phase and solved complex interlocking problems between operating sewers, underground utilities, structural integrity of the adjacent building and limited site access. Pulling activities to produce handoffs was new to participants who asked many questions. The final stickies plan was converted to Primavera SureTrack for actual use.

\section{Case 3}

Project Installation of new Magnetic Resonance Imaging (MRI) equipment in renovated M RI section of hospital Phase: Entire project (only 3 months)

Participants: Architect, GC, relevant subs, facilitator Eureka moment: none

Discussion: The architect's description of the intent of project helped everyone better understand the project. The team planned for work to meet the milestones previously established by GC PM on a CPM schedule. These were used to focus discussion.

\section{Case 4}

Project: Heart Catheter Laboratory installation in renovated hospital wing

Phase: From demolition complete to ready to install lab equipment

Participants: Architect, owner, GC PM, all subs, equipment supplier, facilitator

Eureka moment: The team initially discovered that they would be unable to deliver the project when needed by the hospital. Efforts to reduce the duration were unsuccessful until the laboratory equipment supplier offered to complete their work 5 days faster (out of 15) 
if the equipment installation could begin in time to complete by year-end. This increased value for both the hospital and the installation contractor. Discussion: The session was run by the superintendent. The subs knew each other well and had previously installed a similar laboratory in the same hospital a year earlier. They reflected on that experience to refine the approach with effective collaborative interaction The stickies were converted to MS Project for actual use.

\section{Case 5}

Project: New wing on Childrens' hospital Phase: Preparation and Issuing of Construction Documents

Participants: Architect, engineers, GC, facilitator Eureka moment: Smaller breakthrough lead to a significant improvement in scheduling of the reviews. Discussion: New format for "stickies" on wall that included the use of a preprinted calendar on the wall, modification of "suits and boots" (designers and field staff) review procedures, the plan was accepted by all participants.

\section{Case 6}

Project: Medical O ffice Building

Phase: Ground breaking until slab on grade Participants: Architect, owner, GC, relevant subs, facilitator

Eureka moment: The explanation of site limitations by the excavator.

Discussion: Subs were entirely new to each other good portion of session was devoted to "building trust and understanding" what each needed for project success. The team had a difficult time building a phase plan until the excavation contractor explained how site limitations dictated the initial strategy. This clarified the situation so that the phase plan was produced quickly. The stickies converted to SureTrack for actual use.

Lessons learned from these cases:

These cases demonstrate many different ways the original White Paper instructions and theory have been interpreted and applied. Several lessons were apparent from these sessions. More theoretical considerations will be discussed later in the paper.

- There is no single person or staff role best suited to run the session - it depends on team chemistry and who knows the most about what work needs to be done in the selected phase or can best manage the process. The facilitator needs to keep the meeting on track and must not push forward their solutions.

- The size and length of phase selected is very important - too large and complex, with too many players makes the session much less effective - a typical session should be completed in less than 4 hours. Good advice for selecting the first phase is to cut what appears to be reasonable in half.

- It is very important that the session participants come properly prepared and have enough information, experience and authority to make "deals" regarding their performance on the project. See the meeting invitation in the Appendix for an example of the suggested pre-work.

- "Pulling" tasks is probably the hardest for people to understand and accept. The facilitator is frequently questioned and challenged about this. It is an ongoing battle to keep people working from the end of the schedule to the beginning - people just want to plan as they are accustomed. Reverse planning is easier when a clear strategy for the work in the phase has been established.

- The level of detail (size and number of tasks) that will be represented on the wall is always an issue typically it is not a problem as the level of detail is established by the team. They seem to understand what level is necessary to describe their work, both for their own use and so that others grasp the requirements for handoffs.

- Establishing the context helps. An introduction to the project by either the owner or architect makes a difference to the players - seldom do they really know how the client defines "value" on the project. In an unmentioned case, the owner, a developer, explained the financial implications of the project cost and timing to the subcontractors. These implications were much discussed during the day and shaped a variety of choices made by the team.

- There is no simple nor accurate way of immediately determining the overall duration of the phase from the "task durations" that have been added to the "stickies". It is very hard to understand the impact of overlapping tasks, those that start prior to the completion of another task. In most cases, overlaps should be avoided by breaking the first task into subtasks that release work to the following team in established increments. Establish that the durations are in work days, not calendar days. The conversion of the "stickies on the wall" to a usable schedule for a project is essential and often quite difficult to 
accomplish. Typically work by the project manager and scheduler after the meeting is required - in the best cases, accurately reflecting the work of the team, in not so good cases, reflecting the prejudices of the project manager. In any case, the team should not leave until they are confident that they can deliver the work in the time required.

- The W hite Paper states that as the "stickies" are being placed on the wall, "planning breaks out". This is very true and the single most valuable part of the session. Discussion about how the work will be performed and what is required to begin or accomplish each task is very important. The better this information is reflected on the "stickies" the better the results of the session.

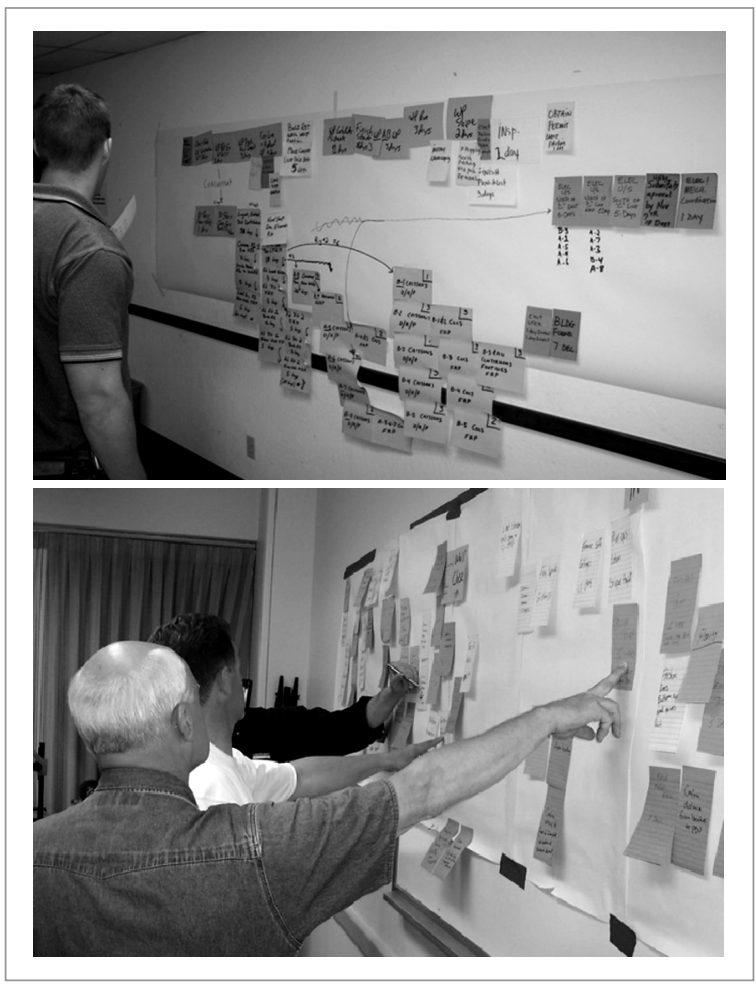

Figure 1. Stickies on the wall with planning occurring

- A facilitator in a phase planning session typically answers the "Why are we starting at the end?" questions but also stresses the need to define handoffs between team members. A facilitator can be most effective by working with the team members to assure they really have defined the start and end of their tasks and have received or given a promise as to what will be in place at the moment of handoff.

- The usual comment from participants in a phase scheduling session is "We have never done this before
- we are always given a schedule and asked to comment on it - never given the opportunity to develop one ourselves. This seems good."

With this understanding of how typical phase planning sessions are conducted, we can look at what the authors see as the most important outcomes of these sessions and then what more might come from a session.

Benefits of phase scheduling as currently practiced:

- Project team gain a better understanding of project value.

- Team has opportunity to meet and become comfortable with others on the team as they plan the work.

- Each member knows what others on the team need to accomplish their tasks, what is important to the success of others.

- The work is planned so that all understand and agree on what is to be done and about when. The team knows how to prepare to make the promises needed to execute the work according to this plan.

- A logical sequence is planned for the work and reasonable durations attached to the activities.

- Gantt charts created from the team's schedule are believable.

- The team knows where the source of the 6 Week Lookahead Plan used to make work ready during the remainder of the phase and project.

\section{Phase planning and a network of commitments}

When the White Paper stated that "planning breaks out" what did it mean? First, the participants in the planning session understand value of the project was and were thinking about the best way to achieve it with minimum waste.

Starting at the end of the phase (SO G poured, Construction D rawings issued) and working back to explain what it took to get there does three things: 1) W hat they will turn over when their task was completed is identified, 2) Their task has been explained to others and later how long it will take established, and 3) They have defined what they need to accomplish their task.

The participants not only defined their task they identified and described "hand offs" both to and from their work. The easy part of phase scheduling is to define and represent the individual tasks - everyone does it and is used to seeing the task represented on a Gantt chart as a line with a beginning and an end indicating 
the start and finish times. Sometimes there is a predecessor and successor activity that identifies what must be done before and after the actual activity.

The difference in phase planning is that the participants discuss these "hand-offs" (and the predecessor and successor activities), understand the impact and negotiate the best way of achieving them. Some phase planning sessions have represented the "hand-offs" ("needs" and "releases") on the "stickies" that are pasted on the wall (see Figure 1) 0 ther sessions simply make sure that the participants understand and accept the "hand-offs" as a necessity for success. In most cases the discussions have resulted in improved or changed ways of performing the work and thus better project performance.

This discussion of "hand-offs" and the acceptance of them by each participant, establishes the basis for a commitment from one performer to another. The team designs the network of commitments, the requests and promises, necessary to complete the work as the add and discuss the tasks and "hand-offs" shown on the wall. This is very different from the typical schedule development where a prepared Gantt chart is provided to the team and they are asked to "comment" on it and very shortly asked to accept it as part of their contract.

O nce a network of commitments, personally developed and accepted by each member of the team is available, project management becomes an effort to see that the network is activated, that the work is made ready to people can make an explicit promise for it to be completed on a specific day. This happens when the team uses a 6 Week Lookahead Plan (6W LAP) to make their work ready. The $6 \mathrm{~W}$ LAP shows the coming six weeks of activities as they were placed on the phase schedule. There are several ways of preparing a 6W LAP from the phase schedule ranging from simply transferring the activities to an Excel spreadsheet (sample below) or, if the phase schedule has been converted to an MS Project or SureTrack format, using the built-in software filters to show just the next six weeks' activities.

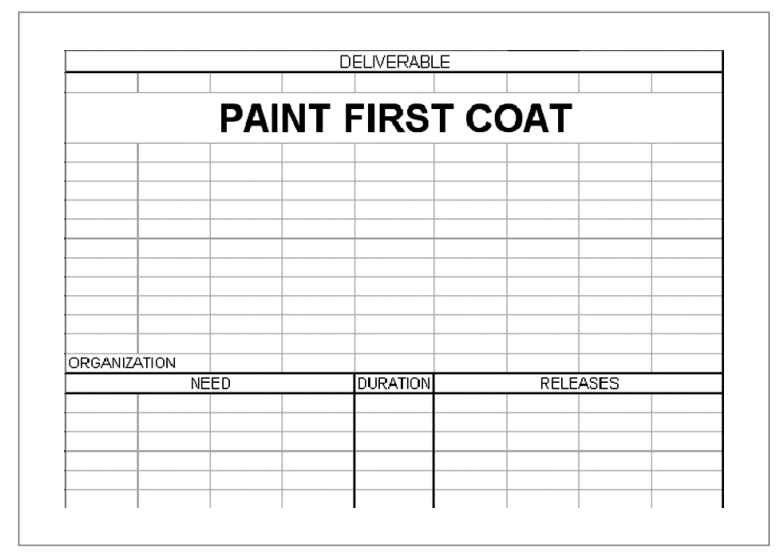

Figure 2. Sample preprinted "stickie"

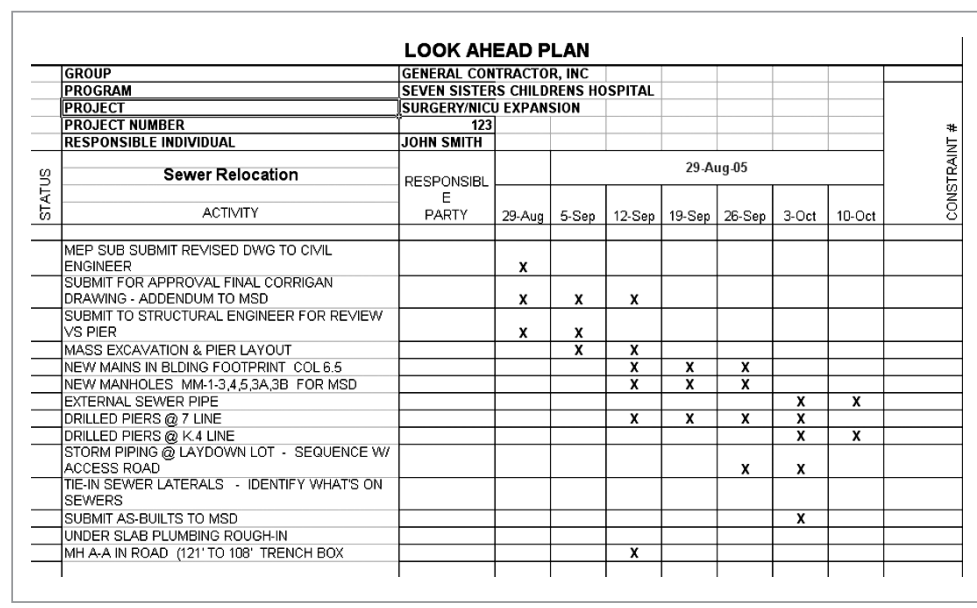

Figure 3. Sample Excel spreadsheet used to represent work for next six weeks 
The 6W LAP serves as a basis for a project meeting where the appropriate leaders examine each of the activities planned for the next six weeks and ask "Are there any reasons why these activities cannot be completed as scheduled?" In other words, can the planned commitments be kept? When the answer is "no", it is considered a constraint and listed with a "promise date" when the relevant person commits to have it removed or to remove it on their own. In this way the network of commitments, first designed in the phase planning session, are continuously monitored and made the focus of project planning.

It is beyond the scope of this paper, but the next step in the Last Planner System involves a similar process where the actual task performers make commitments, not only as to what task they will do, but on what day they will complete it. The successful completion of these commitments is recorded and tracked as Plan Percent Complete - again monitoring the network of commitments that serve as the basis of project success.

\section{Phase planning and value stream mapping}

The authors have worked with several projects and organizations interested in applying the concept of Value Stream Mapping (VSM) to their operations. A detailed discussion of VSM is beyond the scope of this paper but a brief description of how it works will help the reader understand why the authors feel that the same concepts of planning are involved in both.

VSM is typically used in a manufacturing environment where product is produced by a number of machines or fabrication operations. The flow of the product is determined by the location of the machines and the way the product is moved between them. VSM maps this flow and determines the actual time work is done on the product and time that the product is being moved or is waiting, in other words waste. When the waste is identified, a future state map is prepared that eliminates as much of the waste as possible and the team looks at ways to achieve these improvements. Additional parts of the map indicate how information flows to the machines (or their operators) to determine the rate of flow.

O ne of the interesting differences between the manufacturing world and the construction world is that in manufacturing the product flow is determined by the physical location of the machines, in construction the product flow is determined by crew level assignments. The craftsmen are assigned what work will be done when and told to work in different areas at different times in accordance with some plan. On typical jobs this plan is a CPM schedule. As we have seen above, on a project managed with the Last Planner System this plan is developed by the staff actually doing the work. This phase plan can be seen as a value stream map demonstrating the flow of work from one activity to another, though related more by time than physical location. The addition of task durations and the allocation of float is similar to the VSM approach of determining cycle time and overall time at a work station. Similar discussions take place as a team develops a phase plan or works out the detail of a VSM.

Both phase planning and VSM rely on the concept of pull to provide a map or plan that does only the necessary work to accomplish the goals. By doing this, much of the unnecessary additional effort (waste) is eliminated.

\section{Conclusions}

The authors started working with teams to implement "phase scheduling" as described in White Paper \#7, as our work progressed we realized that the effort was accomplishing much more than "scheduling" - it had become "planning". N ot only planning by the project planner and project leaders but by the team that would actually do the work. We believe that this is a critical step forward in understanding how projects can be completed more successfully.

\section{Acknowledgements}

The authors have worked with a number of different organizations and project teams while assisting in conducting phase planning sessions - in all of those sessions the participants have acted in a helpful and learning manner. We thank all of them for demonstrating to themselves and to us that phase planning really brings a new dimension to project planning.

\section{References}

Ballard G. (2000), "Phase Scheduling” LCI White Paper \#7 Lean Construction Institute, Berkeley, CA. Rother, Mike and Shook, John. (2003), Learning to See - Value-Stream M apping to Create Value and Eliminate Muda. The Lean Enterprise Institute, Brookline, Mass. 